\title{
O sentido de prudência na Ética de Espinosa
}

\section{The sense of prudence in the Spinoza's Ethics}

DOI: https://doi.org/10.20873/rpv6n1-91

\author{
Adriana Chimenez Aviles de Lima \\ Orcid: https://orcid.org/0000-00021575-0678 \\ Email: adrianadilima@gmail.com
}

\begin{abstract}
Resumo
Este artigo propõe-se a analisar o sentido de prudência na Ética de Espinosa. Será examinado o modo como o filósofo apresenta sua noção de prudência ao comunicar suas ideias tanto ao não filósofo como a um leitor mais apto à compreensão da "verdadeira filosofia". Espinosa escreve, no Tratado Teológico Político, que, para que seja entendido e ensinar qualquer doutrina ao gênero humano, terá de adaptar seus argumentos à compreensão de todos. Assim, sua noção de prudência é uma arte de adaptar sua comunicação ao vulgo e menciona a necessidade de demonstrar essa regra prática através da experiência. Contudo, existe um caminho almejado pelo filósofo que busca a conciliação de uma sabedoria teórica que pretende alcançar uma "prudência mais alta". Este artigo buscará indicar alguns conceitos e considerações presentes na obra de Espinosa em que sua noção de prudência opera e tem suas bases firmadas no campo do conhecimento e da razão, assim como no campo dos afetos e das relações afetivas. A Parte V da Ética considera em seu primeiro axioma o lugar de mudanças que ocorrem em um mesmo sujeito como uma prática inseparável daquilo que Espinosa designa como prudência. Sem a intenção de esgotar a apresentação desse tema no pensamento do filósofo, essa compreensão será o ponto de partida deste trabalho ainda em andamento, para a análise e reflexão da noção e do sentido de prudência espinosana.
\end{abstract}

\section{Palavras-chave}

Espinosa. Prudência. Regra prática. Sabedoria teórica. Vulgo.

\begin{abstract}
This article aims to analyze the sense of prudence in Espinosa's Ethics. It will be examined how the philosopher presents his notion of prudence when communicating his ideas both to the non-philosopher and to a reader more apt to understand "true philosophy". Espinosa writes in the Political Theological Treaty that, in order to be understood and teach any doctrine to mankind, he will have to adapt his arguments to the understanding of all. Thus, his notion of prudence is an art of adapting his communication to the common and mentions the need to demonstrate this rule of thumb through experience. However, there is a path sought by the philosopher who seeks to reconcile a theoretical wisdom that aims to achieve a "higher prudence". This
\end{abstract}


article will seek to indicate some concepts and considerations present in Espinosa's work in which his notion of prudence operates and has its bases established in the field of knowledge and reason, as well as in the field of affections and affective relationships. Part $V$ of Ethics considers in its first axiom the place of changes that occur in the same subject as a practice inseparable from what Espinosa designates as prudence. Without the intention of exhausting the presentation of this theme in the philosopher's thought, this understanding will be the starting point of this work still in progress, for the analysis and reflection of the notion and the sense of Spinoza's prudence.

\section{Keywords}

Espinosa. Prudence. Rule of thumb. Theoretical wisdom. Common.

\section{Introdução}

A verdade é que, para deduzir algo a partir unicamente de noções intelectuais, se requer muitas vezes um longo encadeamento de percepções, além de uma extrema prudência, perspicácia e a maior contenção, tudo coisas que é raro observar-se nos homens, razão pela qual eles preferem ser ensinados pela experiência a ter de deduzir todas as suas percepções de um pequeno número de axiomas e encadeá-las umas nas outras (ESPINOSA, 2004, p. 199). ${ }^{1}$

O termo prudência corresponde ao vocábulo grego phrónesis e deriva do termo latino prudentia, que também equivale a sapientia. ${ }^{2}$ Seguramente, o conceito de prudência sempre foi objeto de reflexão ao longo da história da filosofia, entretanto, seu sentido é constantemente ressignificado. Na filosofia antiga, tanto na tradição platônica quanto na tradição aristotélica, é uma das virtudes principais que, sem dúvida, deixaram suas influências como herança para a história da filosofia no mundo ocidental. 0 conceito de prudência é um dos mais significativos para o pensamento filosófico, percorrendo como um fio condutor o tempo da história antiga e o tempo da modernidade. Embora a própria distância temporal e o contexto histórico e filosófico tragam cada vez mais transformação e complexidade para conceitos já existentes, soma-se ainda uma diversidade de pensadores que contribuíram enormemente para esse fato. Desta

\footnotetext{
${ }^{1}$ Parte V. Citaremos adiante a obra seguida por algarismo romano para as suas partes e a indicação da página na referente tradução.
}

${ }^{2}$ Mora, Tomo III, 2004. 
maneira, não será a nossa intenção abarcar toda essa composição e nos concentraremos na particularidade da modernidade, especialmente com o filósofo Baruch Espinosa.

Na filosofia moderna, a noção de prudência é revigorada pelas considerações de seu sentido prático, ou seja, a prudência exercida no campo efetivo das ações ganha contornos mais evidentes que vão além do saber teórico. Em $O$ príncipe, Maquiavel, considerado um dos desbravadores da modernidade por se distanciar de muitas formas humanistas de examinar a realidade, tanto no campo ético quanto no campo político, escreve, na sua dedicatória a Lourenço de Médici, o quão valioso é o conhecimento das ações dos grandes homens, que ele aprendeu através de uma "longa experiência das coisas modernas e um contínuo estudo das antigas" (MAQUIAVEL, 2001, p. 129). Nas suas duas obras, O Príncipe e Discursos, o filósofo reflete sobre os modos de proceder dos homens, pois é o que possibilita pensar a ação humana. Os termos envolvidos nesta reflexão são, sobretudo, a virtù e a prudência. A primeira, compreendida como indicativa do caráter de cada homem, com suas tendências e inclinações; a segunda utilizada como orientação para intervir num mundo dominado pelas contingências. Intervenção esta que, embora traga em suas bases a qualidade intelectual da prudência, é puro exercício prático de ação.

Seguramente, para Maquiavel, a prudência não se reduz à reflexão, envolve também a decisão de estratégias adequadas e eficientes no plano de ação e de expressão. No terceiro capítulo de $O$ Príncipe, o filósofo florentino demonstra a prudência utilizada como uma regra prática e estratégica para alcançar os objetivos de forma eficiente: “Quem deseja conservar suas conquistas deve ter em mente duas precauções: uma é extinguir o sangue do antigo príncipe; outra é não alterar suas leis e impostos" (MAQUIAVEL, 2001, p. 9).

Na filosofia de Espinosa, filósofo holandês que viveu entre 1632 e 1677, considerado também um dos grandes expoentes da filosofia moderna, o sentido de prudência foi inicialmente utilizado como um princípio que denotava precaução e se servia do termo latino caute, que também pode ser traduzido como prudência. Esse princípio cauteloso indicado por Espinosa foi mencionado em suas correspondências e reconhecido como um preceito. A palavra caute lhe servia como um selo para suas cartas e denotava um tipo de conselho: "Cada carta que 
dirige aos amigos começa com a famosa máxima "Caute" (Seja prudente), que lhe serviu de selo e de lema" (JAQUET, 2008, p. 14, trad. nossa). ${ }^{3}$ Um lema é como se fosse uma norma ou sentença que engloba todas as outras normas por sua concisão, resume um ideal mediante sua demonstração prévia que pretende demonstrar uma unidade principal do que é exposto. Sob esse aspecto, a exposição bem elaborada da significação filosófica desse lema para Espinosa poderá ampliar os horizontes de leitura sobre o tema.

Esse famoso preceito foi a consequência de repetidos acontecimentos notadamente intolerantes em vários momentos na vida de Espinosa, advindos geralmente de instituições que detinham o poder, como o Governo e a Igreja, os quais censuravam seu pensamento político e filosófico questionador e que ele confrontava com a doutrina católica imposta. A sua excomunhão aos vinte e quatro anos de idade, proferida pela comunidade judaica a qual pertencia, também foi uma das lições mais agudas para o filósofo aderir a esse seu preceito, e torna-se mais compreensível quando se conhece as circunstâncias de seu contexto de vida. Sem dúvida, sua cautela em expor seu pensamento filosófico era necessária até para resguardar sua segurança física, e era essa a sua recomendação eminentemente genuína e legítima. Nas várias cartas ao seu correspondente Henry Oldenburg, Espinosa reiterará sua decisão em relação à divulgação de suas teses, que, ele sabia, só poderia lhe trazer problemas.

Quanto à vossa nova pergunta a respeito da origem das coisas e do elo que as liga à causa primeira, compus, sobre esse assunto e sobre a melhoria do entendimento, uma obra inteira; e agora me ocupo em escrevê-la e corrigi-la. Mas às vezes abandono essa obra porque não me decidi sobre sua publicação. Receio, de fato, que os teólogos de nosso tempo fiquem chocados e me ataquem de maneira odiosa como é de seu costume, a mim que tenho horror às polêmicas ${ }^{4}$ (GUINSBURG, J., 2014, p.62).

Entretanto, embora esse preceito tenha significado de cuidado e atenção decorrida das experiências de vida do filósofo, e ainda que em latim a máxima caute remeta etimologicamente à ideia de cautela e precaução, “a fórmula não deve ser entendida como uma forma passional

\footnotetext{
3 “Cada carta que dirige a sus amigos comienza con la famosa máxima "Caute” (Sé prudente) que le servía de sello y lema."

${ }^{4}$ Esta é a sua 6ํㅜ correspondência com Oldenburg, sem data, provavelmente início de 1662, cf. tradução utilizada.
} 
de desconfiança, senão como uma forma racional de prudência" (JAQUET, 2008, p. 15, trad. nossa). ${ }^{5}$ Com efeito, Espinosa buscava uma estratégia para expor seu pensamento sem que isso lhe trouxesse problemas, como dissemos anteriormente. Dessa forma, seu preceito "seja prudente" é uma forma ativa e atenta que o filósofo procura alinhar sua noção de cuidado e prudência com seu modo de conduzir as experiências.

Na primeira regra do Tratado da Reforma do Intelecto, o filósofo atenta: “É bom, conforme a compreensão do vulgo falar e fazer tudo aquilo que nada ofereça de impedimento para que atinjamos nosso escopo". ${ }^{6}$ Assim, na determinação do filósofo para expor seu pensamento de modo prudente e atencioso, vemos o caminho para seu sentido de prudência como regra prática quando age e escreve de maneira estratégica para ser compreendido por um máximo de pessoas. Ao adaptar a linguagem e a comunicação à maneira de pensar dos homens, Chantal Jaquet $(2008$, p. 23) reconhece no filósofo a sua noção de prudência como regra prática, no entanto, a autora compreende que há uma conciliação entre uma prudência prática e uma prudência teórica, definindo esta última como uma virtude do entendimento, como a potência de compreender as propriedades das coisas a partir de sua essência, e essa é a proposta que o filósofo traz a partir das operações que a sua própria noção de prudência pode desencadear.

Assim, seu lema "Seja prudente" tem uma conotação ativa e seu objetivo é afetar e ser compreendido. Seguramente, Espinosa pretende orientar o leitor não filósofo a ter atenção suficiente àquilo que lê, adquirir uma capacidade leitora que desperte a potência de seu pensamento, que busca a persistência na ação e não na passividade, parte intrínseca do ser, compreendida na sua elaboração filosófica da perseveração de sua própria potência inata ao existir. Contudo, há uma outra pretensão de Espinosa que se destina a falar diretamente com o filósofo, para que este busque uma adaptação na sua comunicação ad captum vulgi, ou seja, para que

\footnotetext{
5 "La fórmula no debe ser entendida entonces como una forma pasional de desconfianza, sino como una forma racional de prudencia."

${ }^{6} \mathrm{TEI}, \S 17$. A partir daqui, chamaremos essa obra de TEI, como se convencionou fazer entre os comentadores.
} 
aconteça a compreensão do vulgo, ${ }^{7}$ das massas, naquilo que for exposto. A operação da ação prudente demarcada por Espinosa, que aconselha o filósofo a falar de modo que seja compreendido pelo vulgo, já delimita um campo semântico para o conceito de prudência espinosano que desejamos analisar.

Quando Espinosa destina seu lema "seja prudente" ao filósofo, a noção de prudência espinosana é baseada numa regra prática, pois é pautada mais na experiência do que na razão para se atingir o objetivo proposto, que é buscar ter a compreensão do vulgo. No Tratado da Emenda e do Intelecto, a experiência mostra que, se há mais entendimento do vulgo na comunicação do filósofo, haverá de fato mais afeição e consideração por aquilo que foi comunicado. ${ }^{8} \mathrm{E}$ quando seu lema caute é dirigido ao não filósofo, a noção de prudência é baseada na pretensão de passar da ignorância à sabedoria, e se alinha a um modo de sabedoria teórica, que utiliza uma forma raciocinada para adaptar-se, dentro dos limites do razoável, à maneira de pensar dos homens para que facilite essa passagem (JAQUET, 2008, p. 16-17).

A conciliação de Espinosa acerca da sua noção de prudência, entre sua regra prática e sua sabedoria teórica, revela nesse duplo aspecto o sentido de uma peça importantíssima no significado da palavra caute, pois a prudência espinosana é uma via que pretende direcionar o indivíduo rumo a uma maior perfeição, seu ponto de partida se dá na regra prática que utiliza uma comunicação estratégica, que busca ser apta à compreensão do vulgo.

\section{A noção de prudência na Ética de Espinosa}

Com efeito, reconhecemos uma prudência espinosana audaciosa quando há pretensão em passar da ignorância à sabedoria, com uma sabedoria prática que fornece princípios para que o modo se torne livre, ativo, que possa se identificar com a liberdade, como exposto no

\footnotetext{
7 Cf. Espinosa. Tratado da Emenda do Intelecto, Trad. Novaes, C. 2015, §17: “Conforme a compreensão do vulgo falar e fazer tudo aquilo que nada ofereça de impedimento para que atinjamos nosso escopo (...), acrescente-se de que desse modo, hão de se apresentar ouvidos amigos para ouvir a verdade".

${ }^{8}$ Ibid.
} 
artigo 5 do capítulo VI do Tratado Político: "A prudência de uma vida identificada com a liberdade de uma natureza".

Na Ética, ${ }^{9}$ é possível vislumbrar a condução da prática de uma prudência intrínseca ao homem, ao seu conatus, ${ }^{10}$ orientação essa que pretende ser direcionada pela razão. Nosso propósito aqui é menos o de apresentar uma definição do que é prudência no pensamento de Espinosa do que o de analisar e compreender com que meios essa sabedoria prática opera, para que sirva de via rumo a uma maior perfeição por parte dos modos finitos. ${ }^{11}$ Para tanto, faremos considerações acerca de sua noção de prudência a partir tanto do campo do conhecimento e da razão como do campo dos afetos ${ }^{12}$ e das relações afetivas.

O axioma que inicia a Parte $V$ da obra diz que "se em um mesmo sujeito forem excitadas duas ações contrárias, deverá necessariamente ocorrer uma mudança, ou em ambas ou em uma só, até que deixem de ser contrárias". Para Laurent Bove (2010, p.63), esse lugar de mudanças que ocorrem em um mesmo sujeito "é um lugar vazio de uma vida como singularidade, inseparável de uma prática que Espinosa designará pela noção de prudência”. Tendo em vista o axioma descrito, a necessidade da mudança nas ações que são em um mesmo sujeito é, sem dúvida, uma exigência vital para o próprio sujeito, porque se suas ações contrárias pudessem conviver entre elas ou serem ao mesmo tempo no mesmo sujeito, "ele seria, por isso mesmo, imediatamente destruído" (BOVE, 2010, p. 64).

Ainda na mesma parte da obra, em seu Prefácio, Espinosa afirma que "na duração específica de cada esforço individual para perseverar em seu ser, toda a gente tem experiência dos

\footnotetext{
${ }^{9}$ Adotamos a seguinte notação para as citações dessa obra: Ética: $E$, seguida por algarismo romano para as partes da obra; proposição: P, com seu número em algarismo arábico; definição: def.; demonstração: dem.; axioma: ax.; escólio:esc.; e corolário:cor. Além disso, para efeito de citação de outras obras de Espinosa, utilizamos as siglas convencionadas entre os seus comentadores.

${ }^{10}$ Espinosa aponta conatus como esforço pelo qual toda coisa tende a perseverar no seu ser, e conforme a proposição VII da parte III da Ética, esse esforço é a essência atual dessa coisa.

${ }^{11} \mathrm{Cf}$. $E$, I, P25, corol. "O homem é um modo finito, como todas as coisas particulares existentes, que exprime as afecções dos atributos de Deus, ou seja, modos, pelos quais os atributos de Deus se exprimem de maneira certa e determinada".

${ }^{12}$ Espinosa define os afetos como "as afecções do Corpo pelas quais a potência de agir do próprio corpo é aumentada ou diminuída, favorecida ou coibida, e simultaneamente as ideias dessas afecções" ( $E$, III, def.3).
} 
remédios para os afetos". Desta forma, para Bove (2008, p. 3) "esta experiência dos remédios constitui sempre já uma memória e uma certa inteligência do real que constituem a prática mesmo desse esforço, enquanto ele é necessariamente uma prudência”. Dessa forma, é possível a compreensão da prudência em operação conjunta com a tendência natural de conservação do sujeito, esforço intrínseco para vencer obstáculos tanto internos quanto exteriores à sua existência, para poder expandir-se e realizar-se plenamente.

Ainda inserida no campo afetivo de um indivíduo, a noção de prudência espinosana também aponta para o modo de funcionamento do ser de acordo com os encontros que lhe vão ocorrendo e, dependendo de como se comporta, os efeitos dos seus atos podem até destruí-lo (BOVE, 2010, p. 32). Nas relações entre os modos finitos e suas essências individuais, ou seja, seu conatus, poderá haver uma verdadeira guerra para poder preservar-se, e é necessário certa atitude estratégica ao lidar com os outros corpos. Nesse ponto, a operação prudente dos modos agora se dispõe a trabalhar influenciada pelos agentes externos e da maneira como é afetado. Por conseguinte, é através da experiência que a conduta dessa regra prática se orienta. Esse é um mecanismo importante para se compreender, pois complementa a realização prudente do sujeito, que parte de suas ações internas, mas que também é influenciada pelo contexto externo de suas relações.

Dessa forma, entendemos que o funcionamento da prudência também está externamente disposto, visto que a experiência prática se acumula pelas paixões e vivências. Jaquet complementa que o significado de caute consiste em ter em conta o estado do espírito submetido às flutuações da alma, das paixões, a fim de preparar os espíritos para perceber o verdadeiro, já que "a prudência assim entendida é um prelúdio ao conhecimento e deve então, ceder o passo a outra forma de prudência mais alta" (JAQUET, 2008, p. 21). Entre a experiência realizada para o desenvolvimento da regra prática prudente e a pretensão em alcançar a "prudência mais alta" está a conciliação do filósofo para seu sentido de prudência, que desenvolve de forma particular e dinâmica. 


\section{A relação entre prudência e razão}

A ética espinosana afirma o livre exercício do corpo, da alma e da razão, conforme declara Marilena Chauí na apresentação da tradução da Ética (2015, p.14). 0 exercício livre dessa composição corpo-alma-razão é exposto na última parte da obra.

Com efeito, é nessa possibilidade da prática de uma vida como liberdade, que a prudência espinosana nos interessa. Reconhecemos que, na Ética, o funcionamento da prudência também opera por disposições externas, conforme mencionamos, entretanto, concordamos também que a noção de prudência é uma operação disposta internamente, sua prática é identificada no sujeito como liberdade de uma natureza que se afirma em perseverar na sua própria existência e se direciona rumo à conquista de sua autonomia quando, nos seus encontros, afeta e é afetado; assim, procede ao movimento emancipatório do conhecimento da causa daquilo que ocorre nessa interação afetiva.

Segue, portanto, nessa consideração, analisar se é possível que a operação da prudência espinosana encontre um caminho que concilia uma sabedoria teórica com a pretensão em alcançar uma "prudência mais alta", percurso esse almejado pelo filósofo, conforme apontado por Chantal Jaquet.

Para essa possível condição, Espinosa escreve haver um remédio para os afetos, o qual provém do conhecimento verdadeiro e que está em nosso poder, visto que não se dá nenhuma outra potência da mente além de pensar e formar ideias adequadas. ${ }^{13}$ Por ideia adequada, enquanto é considerada em si e sem relação ao objeto, Espinosa entende aquela que tem todas as propriedades ou denominações intrínsecas da ideia verdadeira. ${ }^{14} \mathrm{O}$ filósofo também afirma que "não há nenhuma afecção do Corpo de que não possamos formar um conceito claro e distinto".15 Com os "remédios" para os afetos em nosso poder, apresenta-se a busca de uma prática de equilíbrio das disposições afetivas. No entanto, é na perspectiva ética que conhece as coisas por suas

\footnotetext{
${ }^{13}$ Cf. $E, \mathrm{~V}, \mathrm{P} 4$, esc.

${ }^{14}$ Cf. $E$, II def. 4.

$15 E, \mathrm{~V}, \mathrm{P} 4$.
} 
causas adequadas, sem se livrar da vida afetiva, que pretendemos averiguar como passar do estado em que somos externamente submetidos àquele em que somos internamente dispostos e autônomos.

Espinosa afirma que, quando os modos finitos se esforçam para se compor em uma organização de encontros com outros corpos, poderá eventualmente haver a condução de afetos ativos, ou seja, passar da paixão para a ação. Essa é uma condição de aprendizado que exige uma prudência, uma estratégia dos modos para perseverar em sua existência quando entram em contato com outros corpos. Usamos o termo estratégia devido as relações entre os indivíduos nem sempre serem harmônicas e necessitarmos de certo planejamento tático para essas composições se equilibrarem ao menos de forma razoável.

É possível vislumbrar a condução da prática de uma prudência que é intrínseca ao homem, ao seu conatus, orientada pela razão, pois busca aquilo que lhe é útil à sua preservação, a qual o direciona às leis de sua própria natureza humana, sendo realizado, assim, quanto mais liberdade houver em suas ações. “Cada um, pelas leis da sua natureza, necessariamente apetece ou tem aversão ao que julga ser bom ou mau". ${ }^{16}$ Quanto mais alguém procurar o que lhe é útil, mais seguirá a natureza de seu conatus, e assim age dotado de virtude, ou seja, segundo as leis da própria natureza. E “agir absolutamente por virtude” não consistirá em nada mais do que "agir, viver e conservar o seu ser [...] sob a conduta da razão, e isso pelo fundamento de buscar o próprio útil", como diz a Proposição 24 de Ética IV ou, como especifica a sua Demonstração, agir "segundo as leis de sua própria natureza", quer dizer, de maneira autônoma.

Espinosa aponta o desejo racional que nasce das nossas ideias adequadas, segundo a dinâmica da razão que busca o que nos é verdadeiramente útil, de modo que nosso esforço para perseverar na existência torna-se mais eficaz. É através do desejo racional que nossa razão se relaciona com nossa afetividade. "O desejo é a tendência interna do conatus a fazer algo que conserve ou aumente sua força" (CHAUI, 1983, p. XVIII). Todavia, nesse esforço para procurar aquilo que nos deixa mais ativos é necessário conhecer tanto a potência como a impotência da

\footnotetext{
${ }^{16} E, \mathrm{IV}, \mathrm{P} 19$.
} 
nossa natureza para escolher, de fato, aquilo que aumenta nossa potência de agir e de pensar no mundo. Nós agimos de forma mais favorável à nossa natureza na medida em que conhecemos o que nos é útil e aumenta nossa potência, significando que, quanto maior for nosso conhecimento, maior será a possibilidade de governarmos nossa vida e nossas paixões, o que nos garante uma ação mais livre. Esse é o começo de um percurso que tem apoio na regra prática da noção de prudência espinosana, criando uma ponte que concilia o sentido de prudência prática e o sentido de prudência como sabedoria teórica, rumo à possibilidade da liberdade que sua ética propõe.

\section{Bibliografia}

Obras de Espinosa

ESPINOSA, B. Ética. Trad. Grupo de Estudos Espinosanos. Ed. Bilíngue. São Paulo: EDUSP, 2015.

. Breve Tratado de Deus, do homem e do seu bem-estar. Trad. Emanuel Angelo da Rocha Fragoso, Luis César Oliva. 1aㅡ ed., 2ª reimp. Belo Horizonte: Autêntica Editora, 2017.

Tratado da emenda do intelecto. Trad. Cristiano Novaes de Rezende. Campinas, SP: Ed. Unicamp, 2015.

. Tratado Teológico Político. Trad. Diogo Pires Aurélio. 3ae ed. Lisboa: Imprensa Nacional-Casa da Moeda, 2004.

. Tratado Político. Trad. Diogo Pires Aurélio. 1a ed. São Paulo: WMF Martins Fontes, 2009.

\section{Correspondências}

GUINSBURG, J. Cunha, N. Spinoza. Correspondência completa e vida. 1ํㅗㄹ. ed. São Paulo: Perspectiva, 2014.

Obras Complementares

BOVE, L. Espinosa e a psicologia social. Belo Horizonte: Autêntica Editora, 2010.

. Da dominação política e de seus remédios. A lição de Espinosa. Conferência Nupsi-USP, 2008.

JAQUET, C. Spinoza o la prudencia. 1aㅡ ed. Buenos Aires: Tinta Limón, 2008.

. A unidade do corpo e da mente: afetos, ações e paixões em Espinosa. Trad. Marcos Ferreira de Paula, Luis César Oliva. Belo Horizonte: Autêntica, 2011.

MAQUIAVEL, N. O Príncipe. Trad. Maria Júlia Goldwasser. 2ª ed. São Paulo: Martins Fontes, 2001, p.129.

MORA, J. F. Dicionário de Filosofia, Tomo III, 2ª ed. São Paulo: Edições Loyola, 2004. 


\section{Adriana Chimenez Aviles de Lima}

Mestranda em História da Filosofia pela Universidade Federal de São Paulo. Especialização em Filosofia Contemporânea e História na Universidade Metodista de São Paulo. Graduada em Filosofia pelo Centro Universitário Assunção-UNIFAI de São Paulo. Graduada em Comunicação Social pela Universidade São Marcos de São Paulo. 